УДК 330.111

\title{
ЭКОНОМИЧЕСКИЙ РОСТ И ЭКОНОМИЧЕСКОЕ РАЗВИТИЕ: ПРОБЛЕМЫ КОЛИЧЕСТВЕННОГО И КАЧЕСТВЕННОГО СООТНОШЕНИЯ
}

\author{
А.Ш. МАРГАРЯН \\ канд. экон. наук, доцент, декан факультета регулирования экономики \\ и международных экономических отношений \\ Армянского государственного экономического университета, \\ г. Ереван, Армения

\begin{abstract}
А.Э. ТАГАРЯН
аспирант кафедры макроэкономики

Армянского государственного экономического университета, г. Ереван, Армения
\end{abstract}

\section{Аннотация}

Экономический рост является одной из важных проблем современной экономики. В рамках исследования была выявлена сущность категорий экономического роста и экономического развития, определень сходства и различия между этими понятиями. Также на основе эконометрического моделирования была изучена взаимосвязь между технологическим прогрессом, институционалной средой и экономическим ростом.

Ключевые слова: Экономический рост, экономическое развитие, технологический прогресс, институц̧иональная среда.

Economic growth is one of the most important problem $s$ of modern economy. Within research the essence of economic growth has been revealed and in comparison with economic development it is presented similarities and distinctions between these categories. Interrelation between technological progress, the institutional environment and economic growth was also studied based on econometric modeling.

Keywords: Economic growth, economic development, technological progress, institutional enviroment.

\section{ВВЕДЕНИЕ}

Обеспечение стабильности экономическоко роста было и остается одним из ключевых проблем современной экономики. Особо следует отметить, почему некоторые страны растут, развиваются, обеспечивая 
улучшение уровня жизни населения, в то время, как другие терпят неудачу. Примечательно, что 1960-е годы часть стран, имеющих средний уровень дохода, уже к 2000 году вступила в ряды тех стран, которые имели относительно высокий уровень дохода, в то время, как другая часть стран мира осталась на прежнем уровне, а некоторые даже "стремительно" снизили свои темпы роста [17]. Ни для кого не секрет, что уровень дохода на душу населения между странами всегда отличался (например, ВВП на душу населения в США в 2014г. составлял 52,118 долл., в то время как в соседней Мексике он составлял всего лишь 16,284 долл., в Сингапуре 78,958 долл., в то время, как в Китае и в Индии соответственно 12,599 и 5,439 долл.) [18]. В этой связи возникает вопрос: какова причина таких неравномерных темпов развития стран? Что такое экономический рост в целом, и как он влияет на различные слои населения? Действительно ли обсуждаемое экономическое явление проявляется только в положительном свете, или оно также может иметь негативные последствия и нести риски, которые мешают реальному экономическому развитию и процветанию стран?

\section{РЕЗУЛЬТАТЫ И ИХ ОБСУЖДЕНИЕ}

В целом, термин рост - понятие относительное, так как для его представления необходимо иметь или выбрать для расчета какой-либо базис, по отношению к которому необходимо рассчитать данный темп роста. В этом смысле не является исключением также понятие “экономический рост", по отношению к которому свое мнение выразил известный экономист С. Кузнец, как об относительной категории. Он считал, что "экономический рост - относительная концепция, для изучения теоретических и практических аспектов экономического явления, которой необходимо сосредоточить внимание на ее относительности" [19].

В экономической литературе имеется множество определений и восприятий экономического роста. Согласно М.В. Сафрончуку экономический рост - это увеличение реального ВВП при полной занятости в результате расширения производственного потенциала страны за определенный период времени [20]. В учебнике, изданном И.В.Липсицем для студентов экономических вузов, экономический рост определяется как устойчивый рост производственных мощностей страны за год [21]. По оценкам аспиранта академии Башкирии Пескова Д.Р. экономический рост в общем виде означает количественное и качественное изменение результатов производства и его факторов (их производительности) [22]. В то же время Н.А. Суворов определил экономический рост как устойчивое повышение совокупного производства товаров и услуг в конкретной экономике [23]. Интересна также концепция 
восприятия понятияэкономический рост С. Кузнеца, согласно которому экономический рост означает [24]:

1. Рост национального дохода.

2. Научно-технический прогресс.

3. Институциональные и идеологические изменения.

Несмотря на то, что экономический рост - важнейший макроэкономический показатель, тем ни менее высокие темпы роста попрежнему не являются достаточным основанием для принятия определенного суждения о развитии страны. Вышеизложенное связано с рядом негативных аспектов, из которых в особенности можно выделить загрязнение окружающей среды и социальное неравенство. Так как экономический рост по сущности - это рост производства товаров и услуг, то, естественно, что это приводит к загрязнению окружающей среды. Согласно кривой Кузнеца рост ВВП на душу населения сопровождается увеличением загрязнения окружающей среды, но, начиная с определенного уровня доходов, взаимодействия между этими двумя показателями меняется, и население начинает нести дополнительные расходы по нейтрализации ущерба, нанесенного окружающей среде [25].

Мы считаем, что логика кривой Кузнеца довольно реалистична, что подтверждается статистикой (таким образом, средняя ожидаемая продолжительность жизни в развитых странах выше, чем в странах с низким уровнем развития, например, в Великобритании и Сингапуре данный показатель составляет 81 и 82 года соответственно, в то время как в Уганде и Зимбабве 58 и 56 лет [26]), однако попытки по нейтрализации ущерба, нанесенному окружающей среде, могут нести "запоздалый" характер, так как ассимиляционный потенциал природы ограничен и в случае загрязнения более, чем его приемлемый уровень, то вернуть его в прежнее естественное состояние становится невозможным, что оказывает негативное влияние на качество жизни населения. Что касается социального неравенства, то следует отметить, что экономический рост разделяет общество на две группы: «победителей» и «проигравших».

Идея Джозефа Шумпетера касательно «творческого разрушения» [27] относится к проблеме, которую можно сформулировать следующим образом: «производственные взаимоотношения, отдельные компании, а иногда и отдельные лица могут понести значительные убытки в результате экономического роста, что порождает социальную напряженность в данных условиях». Таким образом, следует отметить, что обеспечение высоких темпов экономического роста не означает высокий уровень и качество жизни. Поэтому мы считаем, что экономический рост следует оценить не только количественно, но также следует выявить 
качественные результаты. В данном контексте представляет собой интерес для исследования термин "экономическое развитие", который имеет как сходства, так и различия с "экономическим ростом". Сходствами являются:

1. Как экономический рост, так и экономическое развитие являются непрерывными процессами, которые оказывают стимулирующее воздействие на экономику.

2. Оба предполагают повышение эффективности использования ресурсов.

3. Конечным результатом обоих является улучшение качества и условий жизни.

4. Как экономический рост, так и экономическое развитие представляют собой процесс перехода от одного состояния экономики к другому.

Основное различие между экономическим ростом и экономическим развитием заключается в том, что если экономический рост дает количественное описание экономической деятельности, то экономическое развитие является более обшырной категорией, которая пытается описать качественные аспекты экономической деятельности. (Например, социальные, политические и экономические изменения, которые происходят в результате экономического роста) [28].

С целью качественной оценки экономического роста в работе производится оценка корреляционной связи между ВВП на душу населения и индексом человеческого развития (см. рис. 1). Разумеется, рост уровня доходов (для оценки которого в модели используется показатель ВВП на душу населения) приводит, с одной стороны, к росту потребительского спроса и уровня жизни населения, однако с другой стороны, ВВП на душу населения не может дать представления о доходах субъектов, оказавшихся «вне игры» и, соответственно, о качестве жизни и уровне жизни населения. Для решения вышеуказанной проблемы, была оценена существующая обратная взаимосвязь между ВВП на душу населения и скорректированным коэффициентом Джини (см. рис. 1), согласно которой в странах с более высоким уровнем концентрации доходов, более низкий показатель ВВП на душу населения.Так, например, в Беларуси ВВП на душу населения в 2014г. составил 8040 долл. США, а скорректированный коэффициент Джини 0,332; в России эти показатели составили, соответственно, 12736 долл. США и 0,503, в Казахстане 12602 долл. США и 0,368. Для сравнения отметим, что в Судане были зарегистрированы следующие значения указанных показателей: 1926 долл. США и 0,975, а, например, в Норвегии 64004 долл. США и $0,273$.

После промышленной революции, многие экономисты в качестве наиболее важного фактора, способствующему долгосрочному 
экономическому росту, выделяют научно-технический прогресс. В настоящее время пользуется популярностью исследования относительно влияния научно-технического прогресса на экономический рост, который представлен в качестве одного из ключевых факторов для стимулирования роста. Многие теоретики научно-технический прогресс связывают с присущим инновационным потенциалом умов людей, что, в конце концов, является описательной компонентой рабочей силы. Если для инновационных и креативных работ имеются достаточные институциональные условия, то научно-технический прогресс обеспечен. Данную позицию разделяли известные экономисты P. Лукас и Эр. Джонс [29]. Интересно, что, несмотря на большое значение инноваций во многих странах, они не являются важным фактором, влияющим на экономический рост, что дает основания полагать, что ключевым фактором экономического роста является не столько научно-технический прогресс, сколько благоприятная институциональная среда. Об этом свидетельствуют данные таблицы 1, согласно которым, какой-либо четкой закономерности между количеством запатентованных изобретений и ВВП на душу населения не наблюдается.

Таблица 1 - Каличество патентов и ВВП на душу население в течение 2014 года

\begin{tabular}{|r|l|r|r|}
\hline$\#$ & Страна & Каличество Патентов & ВВП на душу населения \\
\hline 1 & Швейцария & 1,480 & 85,617 \\
\hline 2 & Дания & 1,377 & 60,718 \\
\hline 3 & Шведия & 1,984 & 58,899 \\
\hline 4 & Сингапур & 1,303 & 56,284 \\
\hline 5 & США & 285,096 & 54,629 \\
\hline 6 & Канада & 4,198 & 50,231 \\
\hline 7 & Германия & 48,154 & 47,774 \\
\hline 8 & Япония & 265,959 & 36,194 \\
\hline 9 & Казахстан & 1,742 & 12,602 \\
\hline 10 & Беларусь & 652 & 8,040 \\
\hline 11 & РФ & 24,072 & 12,736 \\
\hline 12 & Китай & 801,135 & 7,590 \\
\hline
\end{tabular}

Источник: составлено нами по [12, 13$].$

В таблице 1 представлены каличество патентов и ВВП на душу население в течение 2014 года, по которым можно проследить, что 
взаимосвязь между инновации и экономического роста не однозначно. В Швейцаре, например, где ВВП на душу население в течение 2014-го года был самым высоким в мире (85,617 долл.) каличество патентов был 1,480, в то же время в Китайе ВВП на душу население был 7,590 долл., а каличество патентов 801,135.

Среди стран-членов ЕврАзЭс, представленных в таблице, наименьшее количество запатентованных изобретений в 2014г. было зарегистрировано в Беларуси (652), где ВВП на душу населения составляет 8040 дол. США. Отметим, что начиная с 2010г. количество запатентованных изобретений в Беларуси динамично идет на убыль (с 1759 достигнув до 652) на фоне динамичного роста ВВП на душу населения (с 5819 до 8040 долл. США). Определенный интерес представляют показатели России и Казахстана, у которых почти одинаковый уровень ВВП на душу населения, в то время как количества патентов значительно отличаются, составляя, соответственно, 24072 и 1742.

Функциональная зависимость между индексом человеческого развития (рассчитываемого программой развития ООН) и ВВП на душу населения представляется следующей формулой: $\mathrm{Y}=73,359 \cdot \mathrm{e}^{6,9764 \mathrm{x}}$. Отметим, что корелляционная связь оценивается как нелинейная и показывает, что рост ВВП на душу населения сопровождается ростом индекса человеческого развития. Иначе говоря, рост доходов населения сопровождается ростом уровня жизни. Указанная связь была выявлена с помощью программы Excel. Выборка производилась среди 80 стран c различными уровнями развития. Приведенный ниже график свидетельствует о высоком уровне корреляции между ВВП на душу населения и индексом человеческого развития, составляющей 0,87 единиц.

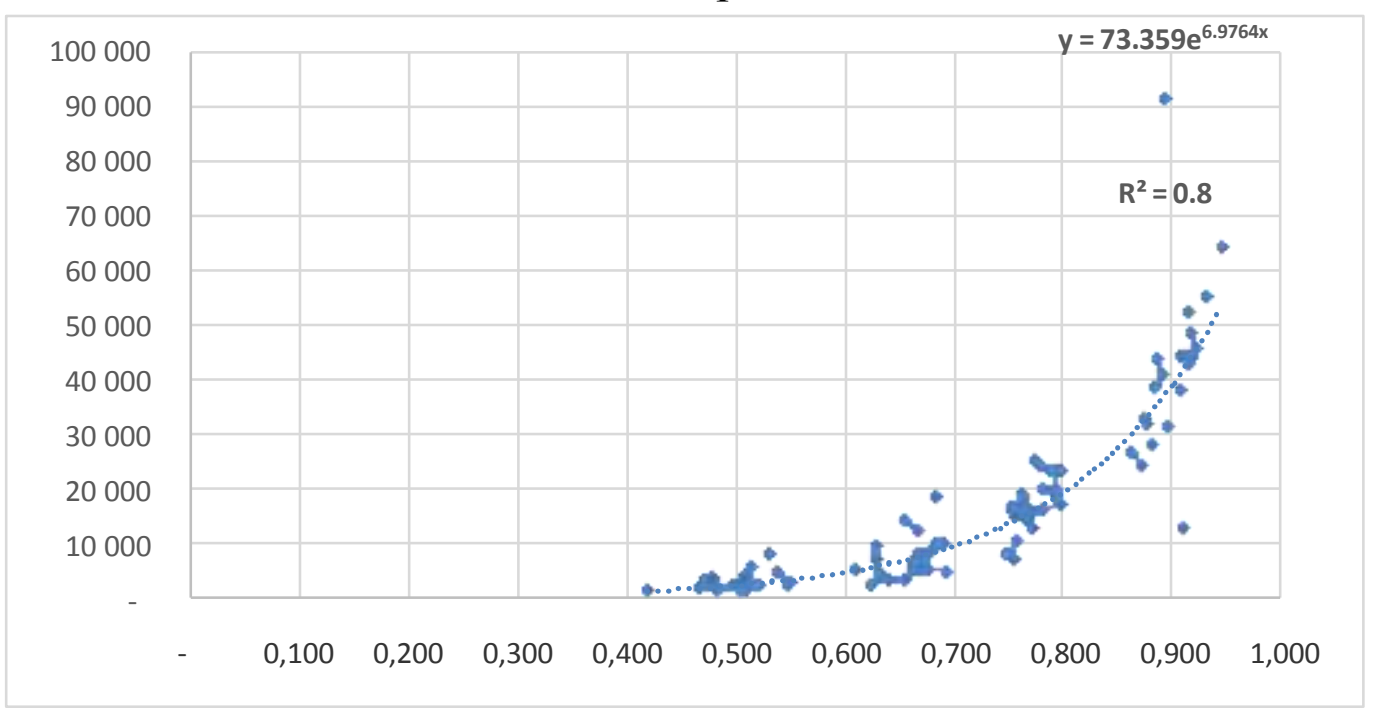

Рисунок 1 - Корреляция между индексами человеческого развития и ВВП на душу населения. Источник: составлено авторами по источникам [11, 12, 14] 
Существует обратная связь между скорректированным коэффициентом Джини и ВВП на душу населения. В странах с низким уровнем концентрации доходов регистрируется высокий показатель ВВП на душу населения и, наоборот. Взаимосвязь между показателями представляется по следующей формуле $\mathrm{Y}=-0,16 \ln (\mathrm{x})+2,0764$.

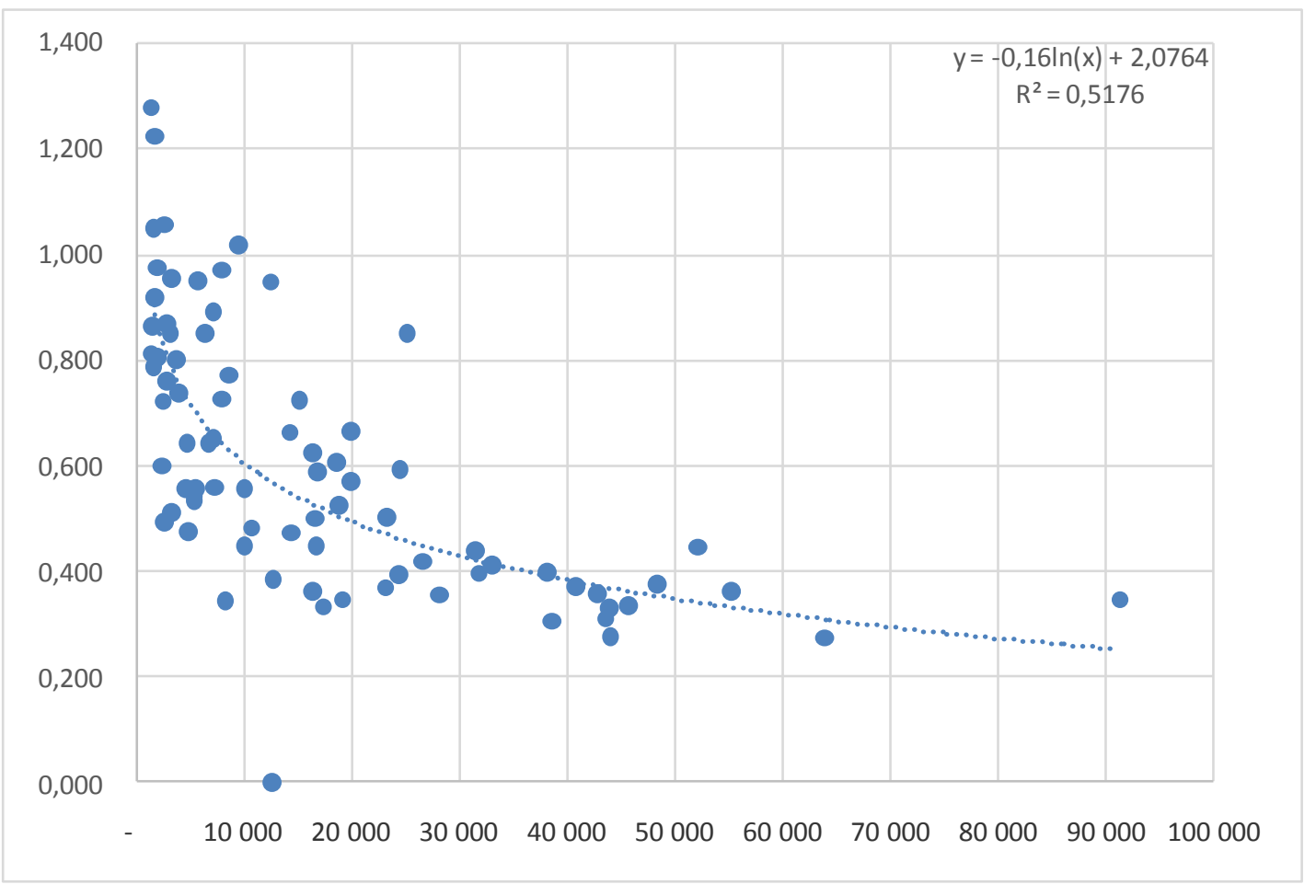

Рисунок 2 - Коррелация между индексом Джини и ВВП на душу населения. Источник: составлено авторами по источникам $[11,13,14]$

Известный экономист, лаурат Нобелевской премии С. Кузнец считает, что научно-технический прогресс является потенциалом, способствующим экономическому росту, который является необходимым, но не достаточным условием. Научно-технический прогресс требует институциональных и идеологических корректировок, чтобы стать реальным фактором, влияющим на экономический рост [30]. Конечно, в 21-м веке страны без инноваций и научно-технического прогресса в плане обеспечения экономического роста будут иметь большие трудности, однако с другой стороны, в результате того же научно-технического прогресса часть участников рынка вытесняются из сферы конкуренции, что приводит к неравномерному распределению доходов населения, бросая тень на восприятие экономического роста как позитивного явления. И именно в данном контексте важную роль играют институты, которые должны стать решением проблемы. 


\section{ВЫВОДЫ}

Под экономическим ростом следует понимать не только количественное изменение конкретных макроэкономических показателей (например, ВВП на душу населения), но также выявление его качественных аспектов. Количественные показатели могут расти, свидетельствуя о темпах развития страны, однако трудно сказать, насколько они отражают изменение качества жизни населения. Поэтому необходимо расширить научные понимание об экономическом росте, как о категории, которая описывает уровень развития страны.

Экономический рост может сопровождаться ухудшением загрязнения окружающей среды и, следовательно, ухудшением качества жизни населения. Обратим внимание, что указанная проблема характерна для стран с низким уровнем развития, где уровень дохода на душу населения низкий. Экономический рост может привести к неравномерному распределению доходов населения и, как следствие, к росту социальной напряженности. Поэтому для обеспечения качественного роста, необходимо создание благоприятной институциональной среды.

Различия в уровнях экономического развития государств мира обусловлены особенностями институциональной среды. Научнотехнический прогресс в этом плане является ключевым фактором экономического роста, однако это также зависит от институциональной системы.

\section{ЛИТЕРАТУРА}

1. "Introduction to modern economic growth", Daron Acemoglu, Department of Economics, Massachusetts Institute of Technology. Princeton University Press, 2009. 1008 Pg.

2. "Economic Growth and the Environment", Tim Everett, MallikaIshwaran, Gian Paolo Ansaloni and Alex Rubin, Defra Evidence and Analysis Series, Paper 2, March 2010.

3. Ronald A. Shearer, "The Concept of Economic Growth", Kyklos 14(4): 1961, Pg. 497-532.

4. "Concepts of Economic Growth and Development. Challenges of Crisis and of Knowledge", Alina-Petronela HALLER Romanian Academy Branch of Iasi, ROMANIA, Economy Transdisciplinarity Cognition, Vol. 15, Issue 1/2012, Pg.66-71.

5. "Long-Term Economic Growth And The History of Technology", JOEL MOKYR, Departments of Economics and History, Northwestern University, Handbook of Economic Growth, 2005, vol. 1, Part B, pp 1113-1180. 
6. Moshe Syrquin, Kuznets and Modern Economic Growth Fifty Years Later, University of Miami, May 2005.

7. «Теневая Экономика и экономический рост - особенности взаимодействия», Пескова Д.Р., аспирант Башкирской академии государственной службы и управления при Президенте Республики Башкортостан, УФА, Российский экономический интернет-журнал.

8. Экономика, Суворов Н.А. / Москва, Московский государственный технический университет гражданской авиации, $2007-47$ с.

9. И.В.Липсиц «Экономиика», учебник для вузов, Москва 2006, C. 437.

10. Сафрончук М.В. «Экономический рост» глава 25 // Курс экономической теории: учебник - 5-е исправленное, дополненное и переработанное издание - Киров: АСА, 2004. - С. 605-644.

11. «Экономический рост и неравенство: институциональный аспект и эмпирический анализ», Т.В. Меркулова. Журнал, Мир России. Социология. Этнология, Выпуск№ 2 / 2000

12. http://data.worldbank.org/indicator/NY.GDP.PCAP.PP.KD

13. http://data.worldbank.org/indicator/SP.DYN.LE00.IN

14. http://data.worldbank.org/indicator/SI.POV.GINI

15. http://hdr.undp.org/en/composite/HDI

16. http://m.forbes.ru/article.php?id=7786

17. Introduction to modern economic growth, DaronAcemoglu, Department of Economics, Massachusetts Institute of Technology, page 4, http://www.ppge.ufrgs.br/giacomo/arquivos/eco02237/acemoglu-2007.pdf

18. http://data.worldbank.org/indicator/NY.GDP.PCAP.PP.KD

19. http://deepblue.lib.umich.edu/bitstream/handle/2027.42/75479/j.14; jsessionid $=238 \mathrm{C} 0 \mathrm{C} 89877$ AA437E2F169D622C9EA83? sequence $=1$, page 506

20. Сафрончук М.В. «Экономический рост» глава 25 , с. 2 , http://mgimo.ru/files/34960/34960.pdf

21. И.В.Липсиц «Экономиика», учебник для вузов, Москва 2006, c. 437

22. «Теневая Экономика и экономический рост - особенности взаимодействия», Пескова Д.Р., аспирант Башкирской академии государственной службы и управления при Президенте Республики Башкортостан, УФА, стр. 1, http://www.e-rej.ru/Articles/2006/Peskova.pdf

23. «Экономика», Н.А.Суворов, Московский Государственный Технический Университет Гражданской Авиации, с. 5, http://storage. mstuca.ru/bitstream/123456789/1999/1/Экономика.20.pdf

24. http://www.undp.uz/ru/download/index.php?type=publication\&id= 150\&parent $=2858 \&$ doc $=99146$, c. 2 . 
25. «Economic Growth and the Environment», Tim Everett, MallikaIshwaran, Gian Paolo Ansaloni and Alex Rubin, Defra Evidence and Analysis Series, Paper 2, March 2010, page 17, https://www.gov.uk/government/uploads/system/uploads/attachment_data/file/6 9195/pb13390-economic-growth-100305.pdf

26. http://data.worldbank.org/indicator/SP.DYN.LE00.IN

27. http://m. forbes.ru/article.php?id=7786

28. "Concepts of Economic Growth and Development. Challenges of Crisis and of Knowledge", Alina-Petronela HALLER Romanian Academy Branch of Iasi, ROMANIA, page 68, http://www.ugb.ro/etc/etc2012no1/ 09fa.pdf

29. "Long-Term Economic Growth And The History of Technology", JOEL MOKYR, Departments of Economics and History, Northwestern University, Chapter 17, page 4, http://faculty.wcas.northwestern. edu/ jmokyr/ Durlauf.PDF

30. Moshe Syrquin, Kuznets and Modern Economic Growth Fifty Years Later University of Miami May 2005, page 7, http://www. rrojasdatabank.info/devplan/Syrquin.pdf

Статья поступила в редакиию 18 декабря 2015 года. 